PURQUERIO, L.F.V.; CECÍLIO FILHO, A.B.; BARBOSA, J.C. Efeito da concentração de nitrogênio na solução nutritiva e do número de frutos por planta sobre a produção do meloeiro. Horticultura Brasileira. Brasília, v. 21, n. 2, p. 185-190, abril/junho 2003.

\title{
Efeito da concentração de nitrogênio na solução nutritiva e do número de frutos por planta sobre a produção do meloeiro
}

\author{
Luis Felipe V. Purquerio; Arthur Bernardes Cecílio Filho; José Carlos Barbosa \\ UNESP-FCAV, Depto. Produção Vegetal, Via de acesso Prof. Paulo Donato Castellane, s/n, 14884-900 Jaboticabal-SP.E-mail: \\ felipesanca@hotmail.com; rutra@fcav.unesp.br
}

\section{RESUMO}

O trabalho foi conduzido em casa de vegetação, na UNESP em Jaboticabal (SP), de junho a novembro de 2001, com o objetivo de avaliar a produção do melão (Cucumis melo var. reticulatus), híbrido Bônus $\mathrm{n}^{\circ} 2$, cultivado em sistema hidropônico NFT, em função da concentração de nitrogênio na solução nutritiva $(80,140,200$ e $\left.300 \mathrm{mg} \mathrm{L}^{-1}\right)$ e número de frutos por planta $(2,3,4$ e livre). O delineamento experimental utilizado foi o de blocos ao acaso, em parcelas subdivididas, com seis repetições. Aos 80 dias após o transplantio, foram observados 2, 3, 4 e 5,1 frutos por planta e, posteriormente na colheita, 2, 2,9, 3,0 e 3,4 frutos por planta, respectivamente para os tratamentos com 2, 3, 4 e fixação livre, sendo esta redução atribuída ao abortamento de frutos. Houve redução no peso médio do $1^{\circ}, 2^{\circ} \mathrm{e}$ $3^{\circ}$ fruto colhido, com o aumento da concentração de nitrogênio. Plantas com o menor número de frutos, apresentaram maior peso médio dos mesmos, porém com menor produção por planta. A maior produção (2.474 $\mathrm{g} /$ planta) foi obtida com $80 \mathrm{mg} \mathrm{L}^{-1}$ de nitrogênio na solução nutritiva.

Palavras-chave: Cucumis melo var. reticulatus, nutrição de plantas, cultivo sem solo, hidroponia, produtividade.

\begin{abstract}
Effect of nitrogen concentration in nutrient solution and number of fruits per plant on yield of melon

The effects of different nitrogen concentrations (80; 140; 200 and $\left.300 \mathrm{mg} \mathrm{L}^{-1}\right)$ and fruit number per plant (2;3;4 and free setting), were investigated on net melon production (Cucumis melo var. reticulatus, Bonus $\mathrm{n}^{\circ} 2$ hybrid). The experiment was carried out in Jaboticabal, São Paulo State, Brazil, in NFT hydroponic system, from June to November, 2001. The experimental design was of randomized split plots, replicated six times. At 80 days after seedling transplant $2 ; 3 ; 4$ and 5.1 fruits per plant were found. However, at harvest there were $2 ; 2.9 ; 3.0$ and 3.4 fruits per plant, relative to $2 ; 3 ; 4$ and free setting per plant treatment. This observed fruit reduction was attributed to fruit abortion. With the increase of nitrogen concentrations a reduction in first, second and third fruit weight was found. Plants with fewer fruits, produced higher average fruit weight and lower yield per plant. The highest yield per plant $(2,474 \mathrm{~g} / \mathrm{plant})$ was obtained with $80 \mathrm{mg} \mathrm{L}^{-1}$ of nitrogen.
\end{abstract}

Keywords: Cucumis melo var. reticulatus, plant nutrition, growth without soil, hydropony, yield.

\section{(Recebido para publicação em 07 de março de 2002 e aceito em 08 de janeiro de 2003)}

$\mathrm{N}$ o início da década de 1990, com a consolidação do cultivo de hortaliças em casa de vegetação, o cultivo do melão rendilhado (Cucumis melo L. var. reticulatus Naud.), surgiu como opção rentável ao produtor, especialmente nos estados de São Paulo e Paraná.

Os melões desse grupo são considerados nobres, por possuírem frutos com aroma e sabor mais acentuados que os melões do grupo inodorus, além de apresentarem a superfície externa da casca toda rendilhada, constituindo-se em mais um atrativo. Essas características acabam por sua vez, atraindo a atenção dos consumidores, que atualmente desejam produtos de qualidade superior, fazendo com que estes melões alcancem boas cotações no mercado nacional e internacional.

No Brasil é pequeno o número de pesquisas com o melão rendilhado, e o aumento do número de produtores tem gerado uma grande demanda por infor- mações técnicas sobre a cultura, como a nutrição mineral e condução da planta.

O nitrogênio é um nutriente que promove muitas modificações morfo-fisiológicas na planta. Está relacionado com a fotossíntese, respiração, desenvolvimento e atividade das raízes, absorção iônica de outros nutrientes, crescimento, diferenciação celular e genética (Carmello, 1999). No meloeiro, a carência de nitrogênio diminui o número de flores hermafroditas, determina formato alongado e coloração clara do fruto, além de um colapso no metabolismo da planta no momento do crescimento do fruto, e limitação do crescimento vegetativo como um todo. Por outro lado, Malavolta et al. (1997) informam que os sintomas de excesso de nitrogênio não estão muito bem identificados, mas que pode ocorrer redução na frutificação.

Entre os componentes de formação da produtividade do meloeiro, tem-se o número de frutos por planta. De acordo com Monteiro \& Mexia (1988) e Martins et al. (1998), normalmente, em cultivo de meloeiro em casa de vegetação (condução da planta na vertical, tutorada e podada), as plantas conseguem desenvolver dois frutos, haja vista, a ocorrência de abortamento natural pela planta. Farias et al. (1988) também constataram que neste sistema de condução, somente dois ou três frutos atingem o estádio de maturação.

Diante das características de cultivo apresentadas anteriormente e das expectativas por melhoria na produção e qualidade dos frutos, o cultivo hidropônico do melão rendilhado constitui-se numa opção tecnológica viável para, de acordo com as vantagens descritas por Hanger (1986), Ueda (1990) e Castellane \& Araújo (1994), contornar condições limitantes ou que dificultam a produção, tais como contaminação elevada do solo por bactérias, fungos 
fitopatogênicos, nematóides e salinização peculiares ao cultivo do meloeiro no solo.

Com base no exposto, o objetivo deste trabalho foi avaliar a influência da concentração de nitrogênio na solução nutritiva e do número de frutos por planta sobre a produtividade do meloeiro.

\section{MATERIAL E MÉTODOS}

O experimento foi conduzido no câmpus de Jaboticabal da UNESP, onde as coordenadas são $21^{\circ} 15^{\prime} 22^{\prime}$ ' Sul, 48 18'58', Oeste e altitude de 575 metros, no período de junho a novembro de 2001 . Durante o período experimental, a temperatura média no interior da casa de vegetação foi de $25^{\circ} \mathrm{C}$ e as médias das mínimas e máximas foram 15 e $33^{\circ} \mathrm{C}$. A média da umidade relativa do ar mínima e máxima foram de 34 e $97 \%$.

A casa de vegetação onde instalouse a cultura era do tipo túnel alto, com lanternim, coberta com filme de polietileno de baixa densidade aditivado, de $150 \mathrm{~mm}$ de espessura, com pé direito de $3 \mathrm{~m}$, largura de 12,80 m, comprimento de $51 \mathrm{~m}$ e sem fechamento lateral e frontal. $\mathrm{O}$ híbrido de melão utilizado foi Bônus $n^{\circ} 2$, sendo semeado dia 18/06/2001 em espuma fenólica $(5,0 \times 5,0 \times 3,8 \mathrm{~cm}) . \mathrm{O}$ transplantio foi realizado aos 22 dias após a semeadura, para um sistema hidropônico tipo NFT (Nutrient Film Technique), em espaçamento de $1,0 \times 0,30 \mathrm{~m}$.

O sistema hidropônico, constituiuse de quatro reservatórios de fibra de vidro, com capacidade para $1500 \mathrm{~L}$ cada, contendo separadamente as quatros soluções nutritivas em avaliação $(80 ; 140$; 200 e $300 \mathrm{mg} \mathrm{L}^{-1}$ de N). Aos reservatórios, estavam ligadas quatro moto-bombas responsáveis pelo bombeamento da solução nutritiva aos canais de cultivo. Estes, constituíram-se de tubos de polipropileno semicirculares com $15 \mathrm{~cm}$ de diâmetro e $4 \%$ de declividade, a fim de permitir o retorno da solução por gravidade para os reservatórios. Os canais apresentavam aberturas circulares de 5 $\mathrm{cm}$ de diâmetro na sua parte superior para a colocação das mudas.

O tempo de funcionamento e de repouso do sistema de bombeamento foi ajustado da seguinte forma: 10' ligado e
20' desligado no período da manhã até 10 horas e 10' ligado e 10' desligado no período subsequente até $18 \mathrm{~h} 30$. À noite, foram feitas duas circulações da solução nutritiva com duração de $10 \mathrm{mi}$ nutos, às $22 \mathrm{~h}$ e $2 \mathrm{~h}$. $\mathrm{O}$ volume de solução nutritiva bombeado por canal de cultivo foi mantido em $3,0 \mathrm{~L} \mathrm{~min}^{-1}$, ficando dentro da faixa ideal de 2,0 a 4,0 L min'-1 (Furlani et al., 1999).

A solução nutritiva utilizada na condução do experimento, baseou-se em Castellane \& Araújo (1994), em relação aos macronutrientes e em Furlani et al. (1999), em relação aos micronutrientes e apresentou a seguinte concentração: $40 ; 165 ; 150 ; 133 ; 100 ; 0,3 ; 2,2 ; 0,6$; 0,3; 0,05 e 0,05 mg L $\mathrm{mg}^{-1} \mathrm{P}, \mathrm{K}, \mathrm{Ca}, \mathrm{Mg}$, $\mathrm{S}, \mathrm{B}, \mathrm{Fe}, \mathrm{Mn}, \mathrm{Zn}, \mathrm{Cu}$ e Mo, respectivamente. Para o preparo das soluções e balanceamento das quatro concentrações de $\mathrm{N}$ avaliadas, foram utilizados os fertilizantes nitrato de potássio, nitrato de amônio, nitrato de cálcio, fosfato monoamônio, fosfato monopotássico, sulfato de potássio, cloreto de potássio, cloreto de cálcio, sulfato de magnésio, magnitra, ácido bórico, sulfato de cobre, cloreto férrico, sulfato de manganês, sulfato de zinco e molibdato de sódio.

A água utilizada na hidroponia tinha pH de 8,1 , condutividade elétrica de 0,1 $\mathrm{dS} \mathrm{m}^{-1}$, e concentrações de nitrogênio nas formas de nitrato, nitrito e amoniacal, respectivamente, 0,013, 0,006 e inferior a $0,001 \mathrm{mg} \mathrm{N} \mathrm{L}^{-1}$. Durante o período experimental, o $\mathrm{pH}$ da solução nutritiva foi mantido na faixa de 5,5 a 6,5 e as condutividades elétricas (C.E.) medidas logo após o preparo das soluções foram de 2,$81 ; 2,81 ; 3,07$ e $2,75 \mathrm{dS} \mathrm{m}^{-1}$, respectivamente para as soluções com diferentes concentrações de nitrogênio. Os valores de C.E. foram restabelecidos, aos iniciais, sempre que constatou-se redução de $10 \%$ aproximadamente, utilizando-se de solução nutritiva estoque com a mesma concentração de nutrientes da solução inicial correspondente. A solução nutritiva foi trocada inicialmente aos 30 dias após o transplantio (DAT) e posteriormente, a cada 15 dias para diminuir efeitos negativos na planta, resultantes de desbalanços nutricionais.

O delineamento experimental foi de blocos casualizados, com parcelas sub- divididas com quatro tratamentos principais (concentrações de nitrogênio) e quatro tratamentos secundários (número de frutos pré-estabelecidos por planta, 2; 3; 4 e livre), em seis repetições, sendo que cada unidade experimental (sub-parcela) foi constituída por oito plantas.

As plantas foram conduzidas em haste única e tutoradas de modo a subirem verticalmente num fitilho plástico. Foram deixados frutos nos brotos a partir do $11^{0}$ nó caulinar para fixação de frutos em quantidade correspondente a cada tratamento, até o $23^{0}$ nó, onde a planta foi podada. Uma vez estabelecido o número de frutos por tratamento, procedeu-se a eliminação dos frutos excedentes. As brotações laterais onde se fazia presente um fruto, foram podadas duas folhas após o mesmo. A polinização foi realizada por abelhas Appis mellifera, colocadas próximas à casa de vegetação no período de floração. Durante o ciclo da cultura foi realizado o controle de doenças causadas por Didymella bryoniae e Oidium spp. e também das pragas vaquinha (Diabrotica speciosa), mosca branca (Bemisia tabaci), larva minadora (Liriomiza sp.) e broca dos frutos (Diaphania nitidalis).

Após 114 dias do transplantio, iniciou-se a colheita que foi realizada durante 15 dias. Avaliaram-se as características: a) área foliar, aos 58 e 114 DAT, utilizando-se apenas os limbos foliares de uma planta útil de cada sub-parcela, em um medidor foliar eletrônico, modelo LI-3100, marca LI-COR; b) massa seca de folhas, avaliada aos 58 e 114 DAT, sendo que todos os limbos foliares de uma planta útil de cada sub-parcela, foram lavados e posteriormente secos em estufa de circulação forçada de ar, à temperatura de $65^{\circ} \mathrm{C}$ por 96 horas, quando procedeu-se a pesagem; c) número de frutos por planta, onde realizou-se a contagem dos frutos aos 80 DAT, com objetivo de saber se os números de frutos fixados por planta atendiam aos valores pré-estabelecidos nos tratamentos e também, número de frutos por planta na colheita; d) produção comercial por planta, obtida pela pesagem de todos os frutos comerciais colhidos, sendo considerados como frutos comerciais, aque- 
les com peso acima de $400 \mathrm{~g}$ e livres de defeitos, conforme sugerido por Nerson et al. (1989); e) peso médio do primeiro, segundo, terceiro e quarto fruto colhido, obtido em ordem cronológica de colheita; f) teor de nitrogênio, fósforo e enxofre, no pecíolo e limbo foliar, obtido no início da fixação de frutos (58 DAT), coletando-se a sexta folha, a partir do ápice, de todas as plantas consideradas úteis das sub-parcelas, separando-se pecíolo e limbo foliar, que posteriormente foram lavados em água deionizada e colocados em estufa de circulação forçada de ar à temperatura de $65^{\circ} \mathrm{C}$, por 96 horas, sendo realizada em seguida determinação dos mesmos segundo metodologia descrita por Malavolta et al. (1997); g) teor de nitrogênio, fósforo e enxofre nas folhas, haste e fruto, obtido aos 114 DAT, coletando-se todas as folhas (limbo foliar), hastes e pecíolos e o primeiro fruto estabelecido de uma planta útil de cada sub-parcela, que posteriormente foram lavados em água deionizada e colocados em estufa de circulação forçada de ar à temperatura de $65^{\circ} \mathrm{C}$, por 96 horas, sendo realizada em seguida determinação dos mesmos segundo metodologia descrita por Malavolta et al. (1997).

Os dados obtidos foram submetidos a análise de variância, aplicando-se o teste de Tukey e regressão polinomial para interpretação, respectivamente, dos efeitos dos fatores número de frutos pré-estabelecidos por planta e concentração de nitrogênio (Banzato \& Kronka, 1995).

\section{RESULTADOS E DISCUSSÃO}

Aos 80 dias após o transplantio, verificou-se a presença de 2; 3; 4 e 5, 1 frutos por planta, respectivamente para os tratamentos com 2, 3, 4 e de fixação livre de frutos por planta. Não foi observado efeito significativo da concentração de nitrogênio na solução nutritiva, nem tão pouco interação dos fatores avaliados sobre o número de frutos por planta. Na colheita, o número de frutos fixados por planta apresentou comportamento semelhante à avaliação feita aos 80 DAT, sendo obtidos 2; 2,9; 3,0 e 3,4 frutos por planta, respectivamente, para as plantas conduzidas com 2, 3, 4 e fixação livre. As médias apresentadas para número de frutos por planta na colheita foram inferiores aos valores pré-estabelecidos, com exceção feita ao tratamento com dois frutos por planta. Maiores percentagens de abortamento de frutos ocorreram à medida em que maior foi o número de frutos fixados pelas plantas aos 80 DAT, atingindo 33\% no tratamento com fixação livre de frutos. Monteiro \& Mexia (1988) trabalhando com fixações de um até cinco frutos por planta de melão cvs. MacDimon e, Harvest King, também observaram uma queda no número de frutos durante o período de frutificação da planta, colhendo-se entre 1 e 2,6 frutos por planta. $\mathrm{O}$ crescimento muito rápido dos frutos e de vários frutos por planta concomitantemente, podem ser justificativas para os valores elevados de abortamento constatados para o meloeiro neste trabalho e também por Monteiro \& Mexia (1988). De acordo com estes autores, entre o $5^{\circ}$ e $15^{\circ}$ dia após a antese, os frutos entram numa fase de crescimento muito intensa, atingindo aproximadamente $80 \%$ do diâmetro final. Esta situação caracteriza uma competição elevada entre os mesmos, promovendo o abortamento de parte dos frutos fixados inicialmente. Além do estresse fisiológico estabelecido pela competição entre frutos da mesma planta, os fatores climáticos são citados por Brandão Filho \& Vasconcellos (1998), como importantes influenciadores do número de frutos em meloeiro. No presente estudo, o período de frutificação foi caracterizado por temperatura média de $25^{\circ} \mathrm{C}$ e média das temperaturas máximas de $33^{\circ} \mathrm{C}$, com picos de temperatura chegando a aproximadamente $39^{\circ} \mathrm{C}$, o que pode ter contribuído para o abortamento de frutos, uma vez que Brandão Filho \& Vasconcellos (1998) sugerem a faixa de 25 a $30^{\circ} \mathrm{C}$ como adequada ao período. Pádua (2001), avaliando os melões 'Bônus n' ${ }^{\circ}$ ', 'Don Carlos' e 'Hy Mark', em solo e em hidroponia, também observou efeito da temperatura sobre a frutificação do meloeiro, sendo maior o número de frutos fixados por planta no cultivo de inverno, enquanto no verão, maior índice de abortamento de frutos foi encontrado, atribuindo às elevadas temperaturas no período de frutificação.
O fator concentração de nitrogênio não influenciou significativamente o teor de nitrogênio no pecíolo e limbo foliar, em avaliação feita aos 58 dias após o transplantio. Os teores médios de nitrogênio observados para pecíolo e limbo foliar foram respectivamente de 27,2 e $41,0 \mathrm{~g} \mathrm{~kg}^{-1}$ e estão dentro da faixa $25-50 \mathrm{~g} \mathrm{~kg}^{-1}$ considerada ideal por Trani \& Raij (1997), para folhas de melão.

Não houve efeito significativo da interação entre concentração de nitrogênio e número de frutos pré-estabelecidos por planta, nem efeito isolado dos fatores sobre o teor de nitrogênio na folha (limbo foliar), na haste e no fruto aos 114 dias após o transplantio, início da colheita. Os teores médios de nitrogênio encontrado na folha, haste e fruto foram de 29,1, 20,6 e 24,8 $\mathrm{g} \mathrm{kg}^{-1}$, respectivamente. Os valores encontrados nesse experimento assemelham-se aos encontrados por Belfort et al. (1986), que trabalhando com melão do grupo inodorus, em solo, observaram 38,6 g $\mathrm{kg}^{-1}$ de nitrogênio aos 30 dias de idade da planta (início da frutificação) com redução para $28,2 \mathrm{~g} \mathrm{~kg}^{-1}$ na colheita. Os teores de nitrogênio encontrados para haste e fruto no início da colheita, também assemelham-se aos observados pelos autores, 17,5 e 27,3 $\mathrm{g} \mathrm{kg}^{-1}$, respectivamente.

O aumento na concentração de nitrogênio na solução nutritiva não afetou a absorção de outros ânions como fósforo e enxofre, fato que poderia ocorrer devido a maior quantidade de nitrogênio na forma nítrica ( $90 \%$ do nitrogênio total) utilizado para compor as soluções nutritivas avaliadas.

Os teores de fósforo e enxofre no limbo foliar e pecíolo, aos 58 dias após o transplantio e teores de fósforo e enxofre no limbo foliar, haste e frutos, na colheita, não foram influenciados significativamente pela interação entre concentração de nitrogênio e número de frutos pré-estabelecidos por planta, assim como também não houve, isoladamente, efeito significativo dos fatores estudados. Os teores médios de fósforo e enxofre encontrados para folha, haste e frutos foram respectivamente 5,2; 5,1 e 5,6 $\mathrm{g} \mathrm{kg}^{-1}$ de fósforo e 2,6; 2,2 e 2,6 g $\mathrm{kg}^{-1}$ de enxofre. 
Tabela 1. Médias de massa seca de folhas (MSF) e área foliar (AF) no início da colheita (114 dias após o transplantio) e de produção comercial de frutos por planta (PROD), peso do primeiro, segundo, terceiro e quarto frutos fixados pelo meloeiro, 'Bônus $\mathrm{n}^{\circ} 2^{2}$ ', cultivado em hidroponia, em função do número de frutos pré-estabelecidos por planta. FCAV-UNESP, Jaboticabal (SP), 2001.

\begin{tabular}{|c|c|c|c|c|c|c|c|}
\hline \multirow{2}{*}{$\begin{array}{c}\mathrm{N}^{\circ} \text { de frutos } \\
\text { pré-estabelecidos } \\
\text { por planta }\end{array}$} & \multirow{2}{*}{$\begin{array}{c}\text { MSF } \\
\text { (g/planta) }\end{array}$} & \multirow{2}{*}{$\begin{array}{c}\text { AF } \\
\left(\mathrm{cm}^{2} / \text { planta) }\right.\end{array}$} & \multirow{2}{*}{$\begin{array}{c}\text { PROD } \\
\text { (g/planta) }\end{array}$} & $1^{\circ}$ fruto & $2^{\circ}$ fruto & $3^{\circ}$ fruto & $4^{\circ}$ fruto \\
\hline & & & & \multicolumn{4}{|c|}{ (g/fruto) } \\
\hline 2 & $53,4 a^{1}$ & $7.780,3 \mathrm{a}$ & $1.670 c^{1}$ & 831 a & 846 a & -- & -- \\
\hline 3 & $48,8 \mathrm{ab}$ & $7.139,7 \mathrm{ab}$ & $2.045 \mathrm{~b}$ & $706 \mathrm{~b}$ & $651 \mathrm{c}$ & 691 a & -- \\
\hline 4 & $47,4 \mathrm{~b}$ & $7.649,4 \mathrm{ab}$ & $2.642 a$ & $686 \mathrm{~b}$ & 679 bc & $632 a$ & 585 \\
\hline livre & $52,5 \mathrm{ab}$ & $6.949,4$ b & $2.327 \mathrm{ab}$ & $717 \mathrm{~b}$ & $730 \mathrm{~b}$ & 689 a & 578 \\
\hline C.V. (\%) & 13,9 & 13,4 & 20,1 & 8,2 & 11,1 & 12,8 & -- \\
\hline
\end{tabular}

${ }^{1}$ Médias na coluna, seguidas de mesma letra, não diferem entre si, pelo teste de Tukey $5 \%$.

Não houve efeito significativo da interação entre concentração de nitrogênio e número de frutos pré-estabelecidos por planta sobre a massa seca de folha e área foliar, aos 114 dias após o transplantio (início da colheita). O fator concentração de nitrogênio, também não exerceu, isoladamente, efeito significativo sobre a massa seca de folhas e área foliar aos 58 e 114 DAT. Possivelmente, a ausência de efeito significativo do nitrogênio sobre o crescimento da parte aérea (massa seca de folha e área foliar), a qual responde pelo dossel fotossintético $\mathrm{e}$, consequentemente, pelo potencial produtivo da planta, pode ser devido à elevada densidade de plantio utilizada, 33.333 plantas por hectare. Menores densidades, $24.000,25.000$ e 27.700 plantas $\mathrm{ha}^{-1}$, foram adotadas, respectivamente, por Monteiro \& Mexia (1988), Cecílio Filho \& May (2000) e Pádua (2001).

Ao contrário do nitrogênio, o número de frutos pré-estabelecido por planta influenciou a massa seca de folhas e área foliar, obtidas aos 114 DAT (Tabela 1), observando-se tendência de redução da área foliar, à medida que o número de frutos fixados por planta foi maior. Este resultado pode ser explicado pela força de drenos na planta, pois frutos são drenos prioritários e a partição de assimilados entre as diferentes partes da planta mostrou ser tanto mais favorável aos frutos, quanto maior força dos mesmos como dreno, estabelecida pelo número crescente de frutos na planta.

Para a característica peso médio do primeiro, segundo e terceiro fruto colhido, não foi observado efeito significativo da interação entre concentração de nitrogênio e número de frutos por planta. A menor concentração de nitrogênio $\left(80 \mathrm{mg} \mathrm{L}^{-1}\right)$ proporcionou peso médio do primeiro fruto de $826 \mathrm{~g}$. O aumento na concentração de nitrogênio até $237 \mathrm{mg} \mathrm{L}^{-1}$ determinou redução no peso do primeiro fruto, quando a partir de então tende a manter peso médio próximo a 675 gramas. Para o segundo fruto, a menor concentração de nitrogênio (80 $\mathrm{mg} \mathrm{L}^{-1}$ ) proporcionou peso de 816 $\mathrm{g}$, apenas $10 \mathrm{~g}$ a menos que o peso médio do primeiro fruto. Reduções no peso médio do segundo fruto foram percebidas mediante aumento na concentração do nitrogênio na solução nutritiva, atingindo aproximadamente, 665 gramas com $248 \mathrm{mg} \mathrm{L}^{-1}$ de nitrogênio. $O$ aumento na concentração de nitrogênio da solução nutritiva, determinou decréscimos lineares no peso médio do terceiro fruto, que apresentou na menor concentração de nitrogênio peso de $715 \mathrm{~g}$ (Figura 1). De maneira geral, observa-se que os frutos estabelecidos mais próximos ao ápice da planta tiveram suas médias de peso reduzidas, isto é, os primeiros frutos fixados obtiveram maior peso. Considerando o peso do primeiro fruto fixado pela planta na menor concentração de nitrogênio e comparando-o com o peso do terceiro fruto fixado, na mesma concentração de nitrogênio, nota-se uma redução de $13,4 \%$ no peso dos frutos.

$\mathrm{O}$ fator número de frutos pré-estabelecido por planta também influenciou significativamente o peso do primeiro, segundo e terceiro fruto colhido. Maior peso do primeiro e segundo fruto colhido foi obtido em plantas com 2 frutos, diferindo significativamente dos demais. Para o terceiro fruto colhido, não foi encontrada diferença significativa em seu peso, mediante o diferente número de frutos pré-estabelecidos por planta (Tabela 1). Os resultados observados concordam com Monteiro \& Mexia (1988), que também verificaram redução no peso médio de frutos à medida em que cresceu o número de frutos colhidos por planta, atribuindo ao resultado observado à menor relação área foliar por fruto. No presente trabalho, os pesos médios dos frutos, observados na Tabela 1 , foram inferiores aos que Fonseca (1994) relata para melões do grupo reticulatus (1,0 a 1,5 kg). Outros autores, Monteiro \& Mexia (1988), Factor (2000), Cecílio Filho \& May (2000) e Gusmão (2001), também obtiveram frutos com peso superior a 1,0 $\mathrm{kg}$, para melões desse grupo, possivelmente devido às menores densidades de plantio adotadas. Em melão, as altas densidades de plantio proporcionam grande número de frutos por área, mas de peso e número de frutos por planta reduzidos (Robinson \& Decker-Walters, 1997). Resultados semelhantes foram observados por Paris et al. (1988), com o melão Galia, Farias et al. (1988) e Grangeiro et al. (1999), ambos, com melão do grupo inodorus.

A produção comercial de frutos por planta não foi influenciada significativamente pela interação entre concentração de nitrogênio e número de frutos fixados por planta. $\mathrm{O}$ aumento na concentração de nitrogênio na solução nutritiva promoveu redução na produção comercial de frutos de melão por planta (Figura 2), correspondendo ao observado para peso médio de frutos.

Não se constatou diferença significativa para massa seca de folha em fun- 
ção do aumento da concentração de nitrogênio na solução nutritiva, porém, verificou-se incremento de $11,5 \%$ na massa seca de folha entre as concentrações de $80 \mathrm{mg} \mathrm{L}^{-1}\left(47,7 \mathrm{~g} \mathrm{planta}^{-1}\right)$ e 300 $\mathrm{mg} \mathrm{L}^{-1}\left(53,2 \mathrm{~g} \mathrm{planta}^{-1}\right)$ de nitrogênio. Percebe-se, portanto, que à medida que se aumentou a concentração de nitrogênio na solução nutritiva, maiores foram os percentuais de massa seca da parte aérea (folhas e haste) em relação ao total acumulado pela planta, com reflexo negativo sobre o acúmulo de massa seca de fruto (Figura 3).

Descarta-se a possibilidade de diminuição da produção da planta em decorrência indireta de aumento na condutividade elétrica (C.E.) da solução nutritiva, em virtude do incremento nas concentrações de nitrogênio. Os valores de C.E. observados nas soluções avaliadas, com valores iniciais de 2,75 $\mathrm{dS} \mathrm{m}{ }^{-1}$ a 2,92 $\mathrm{dS} \mathrm{m}^{-1}$ (com variação de $10 \%$ ), são condutividades elétricas situadas dentro da faixa de 2 a $3,5 \mathrm{dS} \mathrm{m}^{-1}$, indicadas por Furlani et al. (1999), como adequadas ao cultivo do meloeiro.

A menor concentração de nitrogênio, $80 \mathrm{mg} \mathrm{L}^{-1}$, proporcionou uma produção de $2.474 \mathrm{~g} /$ planta. A produção de frutos por planta, para o híbrido Bônus $\mathrm{n}^{\circ} 2$, foi semelhante à obtida por Cecílio Filho \& May (2000), $2.453 \mathrm{~g} / \mathrm{planta}$ e superior aos $1.550 \mathrm{~g} /$ planta obtidos por Pádua (2001). No entanto, devido à maior densidade de plantio, 33.333 plantas/ha, utilizada neste trabalho, a produtividade estimada foi de $82,5 \mathrm{t} \mathrm{ha}^{-1}$, $35 \%$ superior a alcançada por Cecílio Filho \& May (2000), que cultivaram melão no espaçamento de 1,0 x 0,40 m, e muito superior à faixa de produtividade citada por Fonseca (1994) como satisfatória (27 a $45 \mathrm{t} \mathrm{ha}^{-1}$ ), para melões do grupo reticulatus. Deve-se considerar que, embora a produção de frutos por planta seja semelhante à obtida por Cecílio Filho \& May (2000), a concentração de nitrogênio na solução nutritiva neste trabalho, que possibilitou alcançar a maior produtividade, foi inferior à concentração utilizada por aqueles autores, $200 \mathrm{mg} \mathrm{L}^{-1}$, tendo os demais nutrientes a mesma concentração nos diferentes trabalhos. Também, a concentração de $80 \mathrm{mg} \mathrm{L}^{-1}$ de nitrogênio na solução nutritiva, maximizadora de

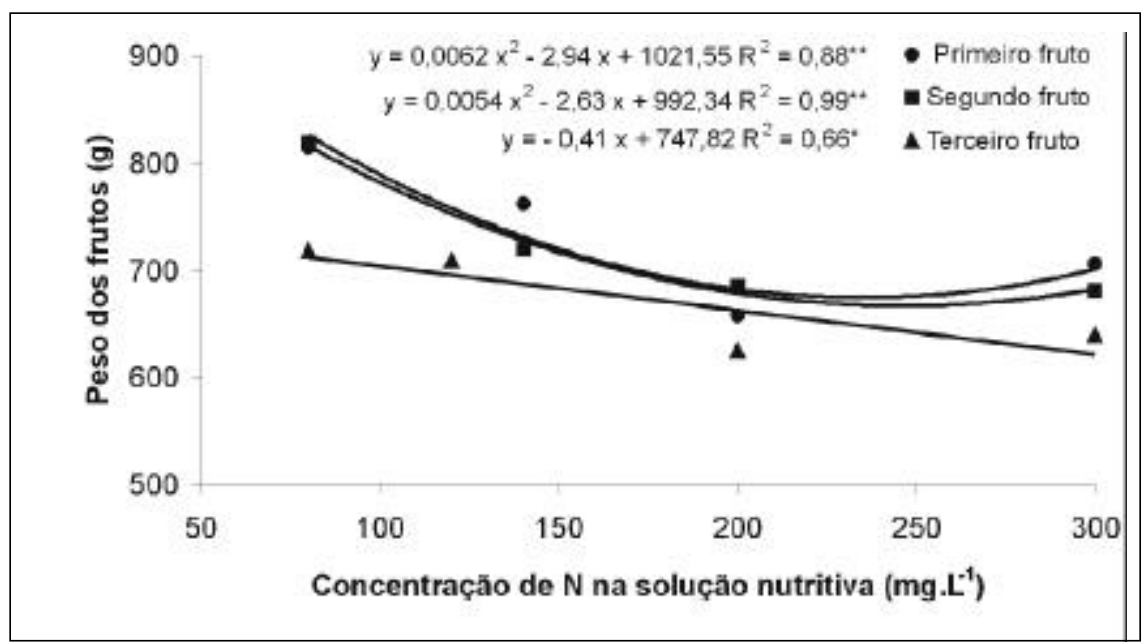

Figura 1. Peso médio do primeiro, segundo e terceiro fruto colhido em meloeiro, Bônus to 2, cultivado em hidroponia, em função da concentração de nitrogênio na solução nutritiva. FCAV-UNESP, Jaboticabal (SP), 2001.

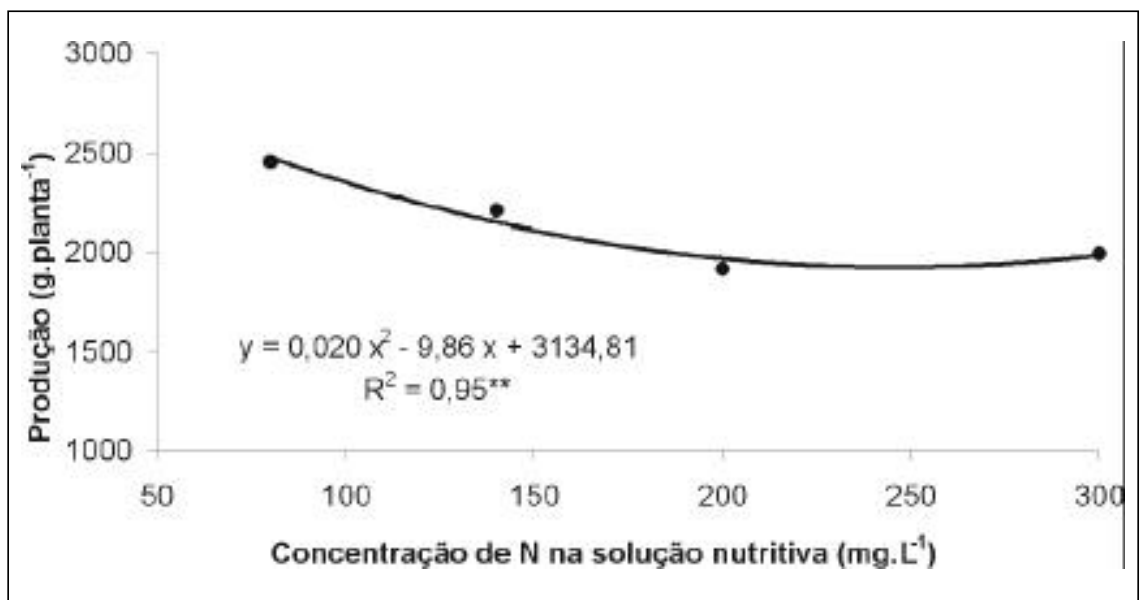

Figura 2. Produção comercial de frutos por planta de meloeiro, Bônus no 2 , cultivado em hidroponia, em função da concentração de nitrogênio na solução nutritiva. FCAV-UNESP, Jaboticabal (SP), 2001.

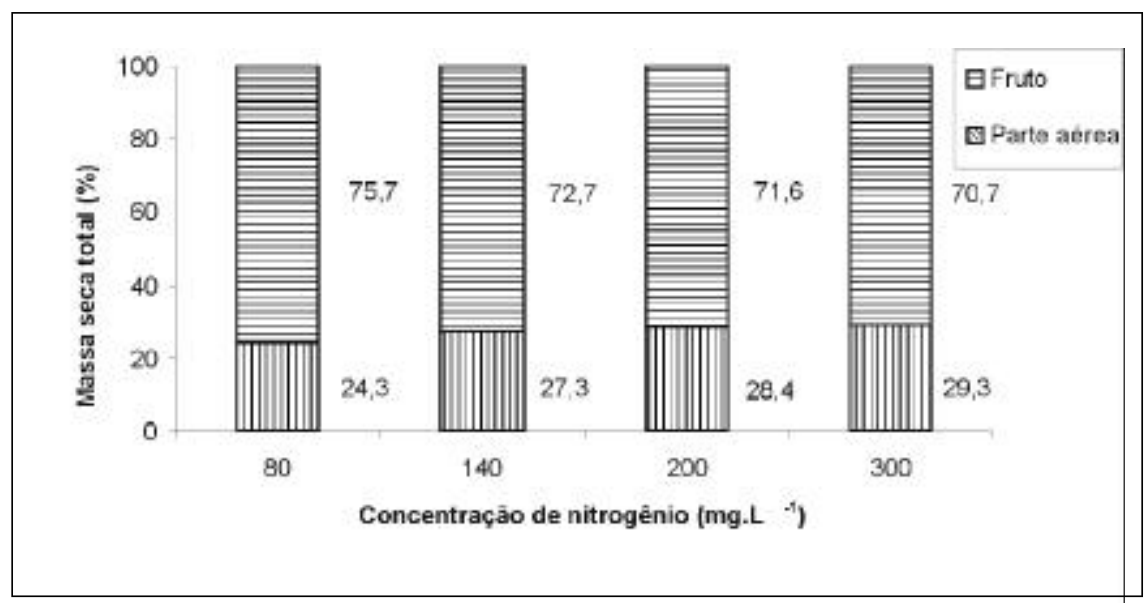

Figura 3. Distribuição percentual da massa seca da parte aérea (folhas e hastes) e de fruto, de plantas do meloeiro, Bônus $n^{\circ} 2$, cultivado em hidroponia, em função da concentração de nitrogênio na solução nutritiva. FCAV-UNESP, Jaboticabal (SP), 2001. 
produtividade encontra-se abaixo dos valores recomendados para melão por Sasaki (1992), Castellane \& Araújo (1994) e Pardossi et al. (1994), respectivamente, de 223; 170 e $130 \mathrm{mg} \mathrm{L}^{-1}$. Possivelmente, as diferenças refletem as condições climáticas da época ou região de cultivo, especialmente de temperatura.

Temperaturas elevadas, respeitandose o limite adequado à cultura e outros fatores controladores dos processos de metabolismo celular, transpiração e absorção iônica, atuam favoravelmente nestes, possibilitando que sejam obtidos teores de nutrientes no tecido foliar e produção de frutos, sob condições de solução nutritiva diluída, semelhantes às soluções nutritivas mais concentradas, desde que naquelas mantenha-se a C.E. da solução nutritiva inicial.

O fator número de frutos por planta também influenciou significativamente a produção comercial de frutos por planta. Maior produção por planta foi obtida nos tratamentos com fixação livre de frutos e 4 frutos por planta, enquanto que menor produção foi constatada para o tratamento com 2 frutos por planta (Tabela 1), demonstrando tendência de queda na produtividade com a diminuição do número de frutos colhidos por planta. Plantas com frutos de maior peso, porém em menor número, não apresentaram produtividade superior à produção daquelas com frutos menores e em maior número, conforme também observado por Monteiro \& Mexia (1998).

Para a densidade e época de plantio adotadas, conclui-se que a concentração de $80 \mathrm{mg} \mathrm{L}^{-1}$ de nitrogênio na solução nutritiva foi suficiente para obter maior peso médio do primeiro, segundo e terceiro fruto, bem como maior produção por planta, verificando-se redução dos mesmos com o aumento de nitrogênio na solução nutritiva. $\mathrm{O}$ incremento de 80 para $300 \mathrm{mg} \mathrm{L}^{-1}$ de nitrogênio na solução nutritiva proporcionou um pequeno aumento na acidez total titulável dos frutos, sem afetar significativamente o teor de sólidos solúveis totais. O aumento no número de frutos por planta determinou menor peso médio de frutos, pro- porcionou incremento na produção comercial de frutos por planta e redução no teor de sólidos solúveis totais.

\section{AGRADECIMENTOS}

A FAPESP, pelo auxílio pesquisa concedido (processo $n^{\circ}$ 2000/01798-6) e aos Professores Drs. Odair Aparecido Fernandes, Jairo Osvaldo Cazetta, Dra. Leila Trevizan Braz, Dr. Modesto Barreto, pelas colaborações técnicas oferecidas durante o desenvolvimento da presente pesquisa.

\section{LITERATURA CITADA}

BANZATO, D.A.; KRONKA, S.N. Experimentação agrícola. 3. ed. Jaboticabal: FUNEP, 1995. 247 p.

BELFORT, C.C.; HAAG, H.P.; MATSUMOTO, T.; CARMELLO, Q.A.C.; SANTOS, J.W.C. Acumulação de matéria seca e recrutamento de macronutrientes pelo melão (Cucumis melo L. cv. Valenciano amarelo CAC), cultivado em latossolo amarelo em Presidente Venceslau, SP. Anais da Escola Superior de Agricultura Luiz de Queiroz, v. 43, n. 1, p. 159-218, 1986.

BRANDÃO FILHO, J.U.T.; VASCONCELLOS M.A.S. A cultura do meloeiro. In: GOTO, R.; TIVELLI, S.W. Produção de hortaliças em ambiente protegido: condições subtropicais. São Paulo: Fundação Editora da UNESP, 1998. p. 161193.

CARMELlO, Q.A.C. Curso de nutrição/ fertirrigação na irrigação localizada. Piracicaba: Departamento de Solos e Nutrição de Plantas, 1999. 59 p. Apostila.

CASTELlANE, P.D.; ARAÚJO, J.A.C. Cultivo sem solo: hidroponia. Jaboticabal: FUNEP, 1994. $43 \mathrm{p}$.

CECILIO FILHO, A.B.; MAY, A. Produtividade de duas cultivares de meloeiro e qualidade de seus frutos, em dois substratos. Horticultura Brasileira, Brasília. v. 18, suplemento. p. 537-538, 2000. FACTOR. T.L. Produção de melão rendilhado em ambiente protegido, inverno-primavera, na região de Jaboticabal. Horticultura Brasileira, Brasília. v. 18, p. 201-202, 2000. Suplemento.

FARIAS, J.R.B.; MARTINS, S.R.; FERNANDES, H.S. Comportamento do meloeiro cultivado em estufa plástica, em diferentes espaçamentos e cobertura do solo. Horticultura Brasileira, Brasília, v. 6, n. 1, p. 52, 1988.

FONSECA, I.C.B. Efeito de três níveis de água em dois períodos do estado de frutificação sobre a qualidade dos frutos de melão rendilhado (Cucumis melo var. reticulatus Naud.), híbrido Cosmos. Botucatu: FCA-UNESP, 1994. 71 p. (Tese mestrado).
FURLANI, P.R.; SILVEIRA, L.C.P.; BOLONHEZI, D.; FAQUIN, V. Cultivo hidropônico de plantas. Campinas: IAC, 1999. 52 p. (Boletim Técnico 180).

HANGER, B.C. The nutrient solution and its preparation. In:__. Hydroponics for schools and the grower. Melborne: Victorian Schoo's Nursery. 1986. p. 21-33.

GRANGEIRO, L.C.; PEDROSA, J.F.; NETO, F.B.; NEGREIROS, M.Z. Qualidade de híbridos de melão amarelo em diferentes densidades de plantio. Horticultura Brasileira, Brasília, v. 17, n. 2, p. 110-113, 1999.

GUSMÃO, S.A.L. Interação genótipo $x$ ambiente em híbridos de melão rendilhado (Cucumis melo var. reticulatus Naud.). Jaboticabal: FCAVUNESP, 2001. 143 p. (Tese doutorado).

MALAVOLTA, E.; VITTI, G.C.; OLIVEIRA, S.A. Avaliação do estado nutricional das plantas: princípios e aplicações. 2. ed. Piracicaba: Potafós, 1997. 319 p.

MARTINS, S.R.; PEIL, R.M.; SCHWENGBER, J.E.; ASSIS, F.N.; MENDEZ, M.E.G. Produção de melão em função de diferentes sistemas de condução de plantas em ambiente protegido. Horticultura Brasileira, Brasília, v. 16, n. 1, p. 24-30, 1998.

MONTEIRO, A.A.; MEXIA, J.J. influência da poda e do número de frutos por planta na qualidade dos frutos e produtividade do melão. Horticultura Brasileira, Brasília, v. 6, n. 1, p. 912, 1988.

NERSON, H; COHEN, R.; EDELSTEIN, M.; BURGER, Y. Paclobutrazol - a plant growth retardant for increasing yield and fruit quality in muskmelon. Journal of the American Society for Horticultural Science, v. 114, n. 5, p. 762-66, 1989. PÁDUA, J.G. Cultivo protegido de melão rendilhado, em duas épocas de plantio. Jaboticabal: FCAV-UNESP, 2001. 108 p. (Tese doutorado).

PARDOSSI, A.; LANDI, S.; MALORGIO, F.; CECCATELLI, M.; CAMPIOTTI, C.A. Studies on melon grown with NFT. Acta Horticulturae, Wageningen, v. 361, p. 186-193, 1994.

PARIS, H.S.; NERSON, H.; BURGER, Y.; EDELSTEIN, M.; KARCHI, Z. Synchrony of yield of melons as affected by plant type and density. Journal of Horticultural Science, v. 63 , n. 1, p. 141-47, 1988.

ROBINSON, R.W.; DECKER-WALTERS, D.S. Cucurbits. New York: CAB International, 1997. $226 \mathrm{p}$.

SASAKI, J.L.S. Hidroponia. In: SEMANA DE AGRONOMIA, 9, 1992, Ilha Solteira. Palestras... 9 p.

TRANI, P.; van RAIJ, B. Hortaliças. In: Recomendações de adubação e calagem para o estado de São Paulo. Campinas: IAC, 1997. p. 157-164. (Boletim Técnico, n. 100)

UEDA, S. Hidroponia: guia prático. São Paulo: Agroestufa, 1990. 50 p. Apostila 